\title{
A note on the occurrence of a crayback stalagmite at Niah Caves, Borneo
}

\author{
Joyce Lundberg ${ }^{1}$ and Donald A. McFarlane ${ }^{2}$
}

\begin{abstract}
:
Lundberg J., McFarlane D.A. 2011. A note on the occurrence of a crayback stalagmite at Niah Caves, Borneo. International Journal of Speleology 40(1), 39-43. Tampa, FL (USA). ISSN 0392-6672. DOI: 10.5038/1827-806X.40.1.5

Crayback stalagmites have mainly been reported from New South Wales, Australia. Here we document a small crayback in the entrance of Painted Cave (Kain Hitam), part of the Niah Caves complex in Sarawak, Borneo. Measuring some $65 \mathrm{~cm}$ in length and $18 \mathrm{~cm}$ in height, this deposit is elongate in the direction of the dominant wind and thus oriented towards the natural tunnel entrance. It shows the classic humpbacked long profile, made up of small transverse segments or plates, in this case the tail extending towards the entrance. The dark blue-green colour down the centre suggests that cyanobacterial growth follows the track of the wind-deflected roof drip. The dry silty cave sediment provides material for accretion onto the biological mat. This is the only example known from Borneo and one of the very few known from outside of Australia.
\end{abstract}

Keywords: crayback, stalagmite, cyanobacteria, phototropic, stromatolitic, Sarawak, Malaysia

Received 7 September 2010; Revised 6 October 2010; Accepted 15 November 2010

\section{INTRODUCTION}

The Niah Caves (3.802 N, 113.773 E) are a large and relatively open system of cavities dissecting the northern outlier of the Gunong Subis limestone massif on the coastal plain $65 \mathrm{~km}$ SSW of the town of Miri, Sarawak, northern Borneo, Malaysia (Figure 1). The principal interest in the caves has been in the massive populations of cave swiftlets (and the associated industry in nest collection - Beavitt, 1992) and, formerly, of bats (Harrison, 1959, 1996; Rabett et al., 2006). Archaeologically the caves are of interest because they are one of the few places in south-east Asia with evidence of continuous human occupation during the late Pleistocene and early Holocene (Barker et al., 2002). However, the geomorphology of the caves remains largely undocumented (Hunt \& Dykes, 2003, studied the geotechnical properties of the guano). The feature reported here is one of the few occurrences outside of Australia of the stromatolitic stalagmitic deposits called "craybacks" or "lobsters" (in reference to their peculiar morphology: Cox et al., 1989a, b; Taborŏsi, 2006) which develop in open natural tunnels in situations of low to moderate light and moderate windiness. No sites from outside Australia have been well documented, but similar features are reported as occurring in New Zealand, Carlsbad Caverns, USA (noted in Cox et al., 1989a), Thailand (Taborŏsi, 2006),

\footnotetext{
${ }^{1}$ Department of Geography and Environmental Studies, Carleton University, Ottawa, Ontario, Canada, K1S 5B6. joyce_lundberg@carleton.ca

${ }^{2}$ W.M.Keck Science Center, The Claremont Colleges, Claremont, CA 91711, USA.dmcfarlane@jsd.claremont.edu
}

and Slovenia (Mulec et al., 2007). None of these other features is illustrated in these reports.

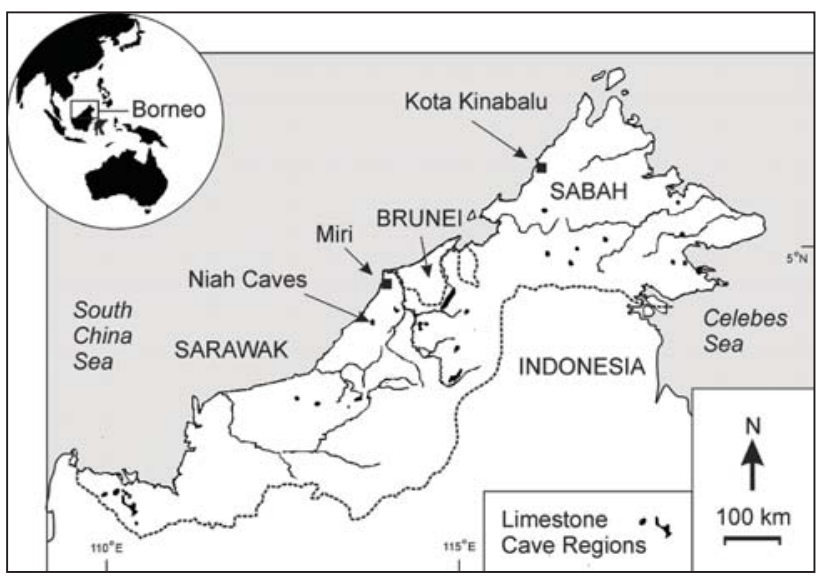

Figure 1. Location of Niah Caves, Sarawak, Malaysia

The term first used popularly was "lobster" for the forms in the caves at Jenolan, New South Wales, Australia (see Cox et al., 1989a). Similar forms at Wombeyan Caves (James et al., 1982), also in New South Wales, were called "craybacks" (as Cox et al., 1989a, indicate, these appellations came from cave guides of the region). In the literature they have been called "stromatolitic stalagmites" (Cox et al., 1989a, b; James et al., 1994) or "phototropic stalagmites" (Cox, 1984). We suggest that the simple designation "crayback stalagmite" be adopted in favour of "lobster" to avoid confusion with biota. The term, being purely descriptive of exterior morphology, also avoids the potential problems associated with the 
genetically-specific terms "stromatolitic stalagmite" or "phototropic stalagmite."

\section{GEOMORPHOLOGY}

Morphologically craybacks are elongate along the main wind direction, have a hump-backed long profile (the taller "head" and the extended "tail"), and in detail are made up of crenulations or "segments" that run transverse to the long axis. The examples from New South Wales, Australia, vary in size from approximately $30 \mathrm{~cm}$ long by $20 \mathrm{~cm}$ tall up to several metres long and tall, and the crenulations are up to about $10 \mathrm{~cm}$ in amplitude (Cox et al., 1989a, b; Rowling, 2006). As with any stalagmite, the travel distance of the drop dictates the resultant splash diameter, so the craybacks in New South Wales are wider under higher roofs. However, the morphology of a crayback is also governed by wind deflecting the drops, hence their elongation in the dominant wind direction.

When damp they have a deep bluish-green coloration that reverts to a powdery grey-green when dry (Cox et al., 1989a, b). Coccoid cyanobacteria were the dominant life form in superficial layers of the Nettle Cave example studied by Cox et al. (1989a, b). Although no fossils of cyanobacteria could be found in the deeper layers the internal structure resembled laminated stromatolites, with layers of calcite (of varying forms - some massive, some coralloid, accreted during wet periods) interspersed with layers of detritus (mainly aeolian material and some insect remains, accreted during dry periods).

The Niah Caves crayback (Figure 2) is in the northern entrance of the two-entrance tunnel cave called Painted Cave, (Kain Hitam) (Figure 3a,b), 4 m inside the drip line, on a floor of dry silty sediment (Figure 4). It is surrounded by old, normally-shaped stalagmite bosses and some roof breakdown blocks. The stalactites in the roof above it are distinctly curved towards the entrance, a feature that may be indicative of either phototropic growth or of wind deflection, but here most likely to be phototropic growth, as indicated by their green colour and tufaceous nature.

The Niah Caves crayback, although smaller than most of the examples in the Australian caves (at 65 $\mathrm{cm}$ long and $18 \mathrm{~cm}$ tall), conforms morphologically to the features of craybacks. The overall form is elongate parallel with the wind and oriented towards the entrance; it has an asymmetric long profile with a taller rounder head, and an extended tail; the surface is marked by the crayback "segments"; and it has the characteristic blue-green colour (the stripe of darker blue-green coloration in Figure 2 marks the most recent path of the wind-deflected roof drip).

There is one ostensible difference between this example and the Australian examples: here the tail extends towards the entrance and thus differs from many of the photographs that can be found on the internet, and from the form as indicated on Rowling's (2006) website, all showing the tail on the inner, darker side. However, the direction of extension of the tail is shown in more rigorous field studies to be quite inconsistent. Of the 28 examples from Nettle Cave studied by Cox et al. (1989a), the whole form is always oriented parallel with the wind direction which is also towards the entrance (north); in spite of this, there is no consistency in the orientation of the tails (about equal numbers face south as north) and the

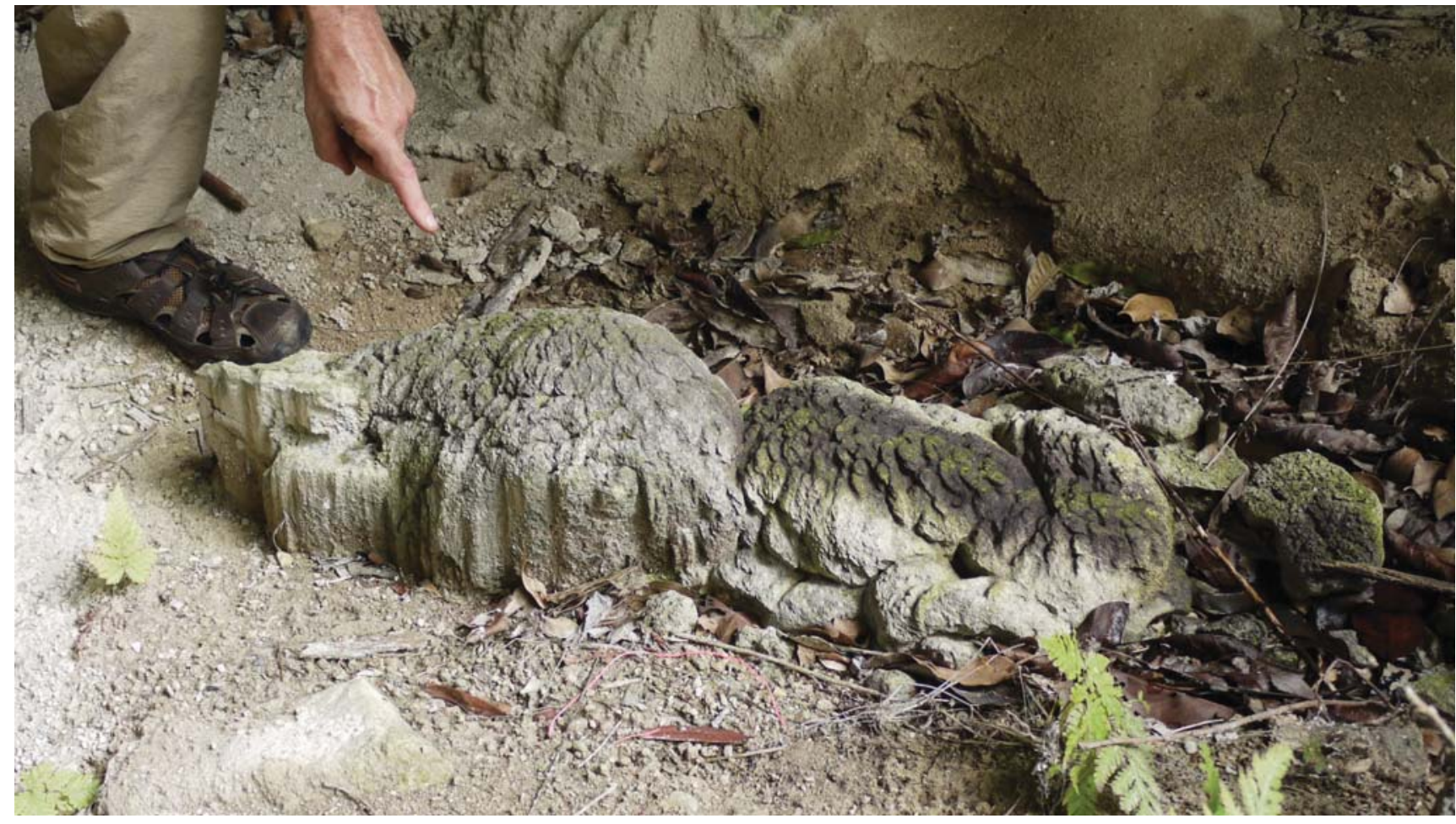

Figure 2. The crayback of Painted Cave, Niah National Park, photographed by natural light. The entrance is to the right, the finger points to the head of the crayback with fluted sides, and the tail extends towards the entrance on the right (bright) side. 


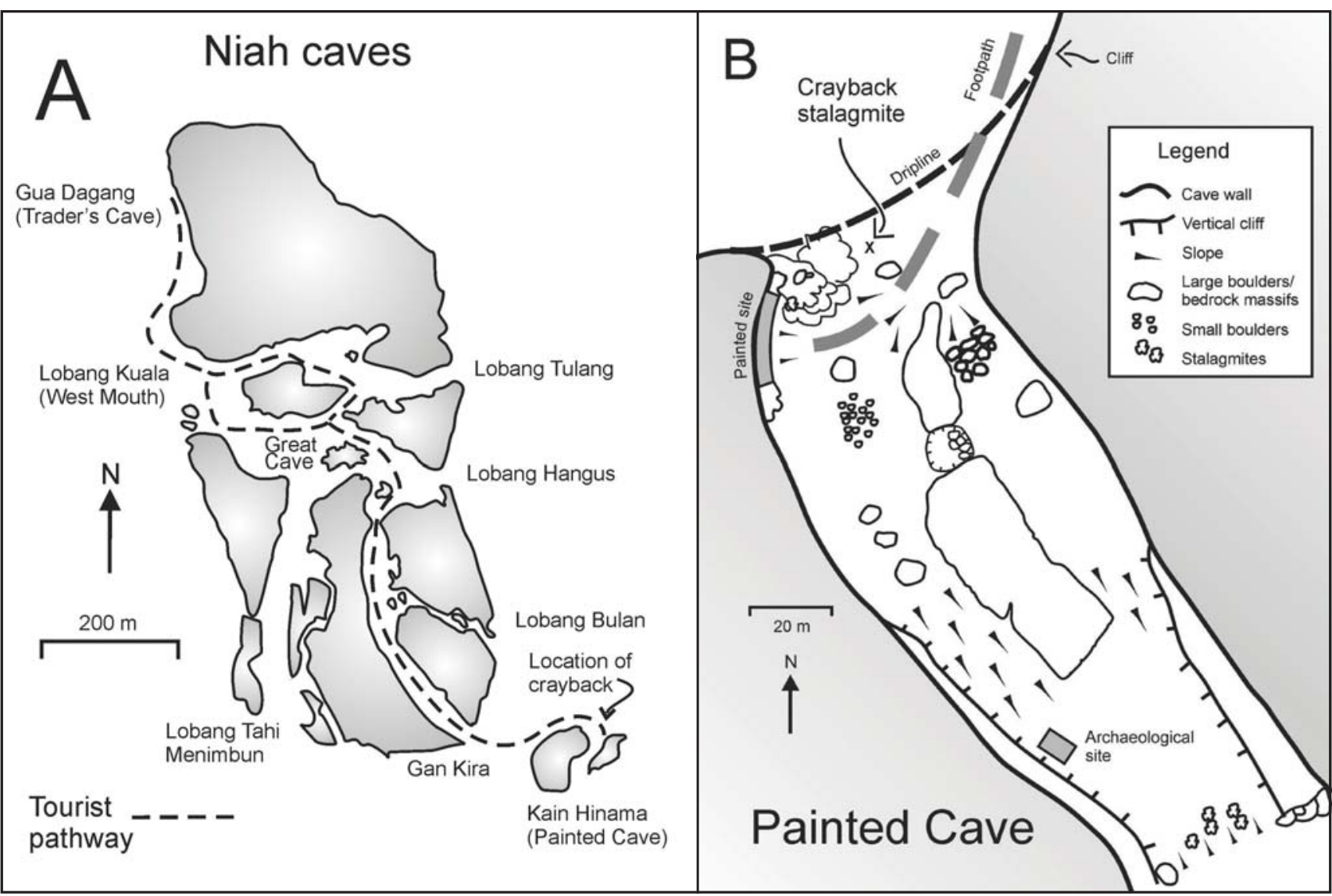

Figure 3. A. Diagram of Niah Caves showing location of the crayback in the northern entrance of Painted Cave (data from on-site tourist information plaque). B. Survey of Painted Cave (drawn from survey data provided by Franz Kessler).

orientation of the tails is not correlated with mid-day light intensity. Thus the Niah Caves example is quite normal.

\section{DISCUSSION}

Explanations for the development of craybacks invoke the relationship of photosynthesis, $\mathrm{CO}_{2}$ fixing and calcite deposition, along with a mechanism for detrital accretion: growth of cyanobacteria causes enhanced precipitation of calcite through photosynthetic removal of $\mathrm{CO}_{2}$ while the cyanobacterial extracellular mucilage acts to trap particulate matter (Cox et al., 1989a). This implies that craybacks should always extend towards the light - exactly the mechanism offered in Rowling's (2006) website: Rowling suggests that photosynthesis on the brighter side enhances deposition of calcite, creating a steep-sided tall head, and that the shape and angle of the tail and its crenulations are governed by the shadow of the head. However, the complexity of tail orientation hints at a rather more complex explanation for the form of

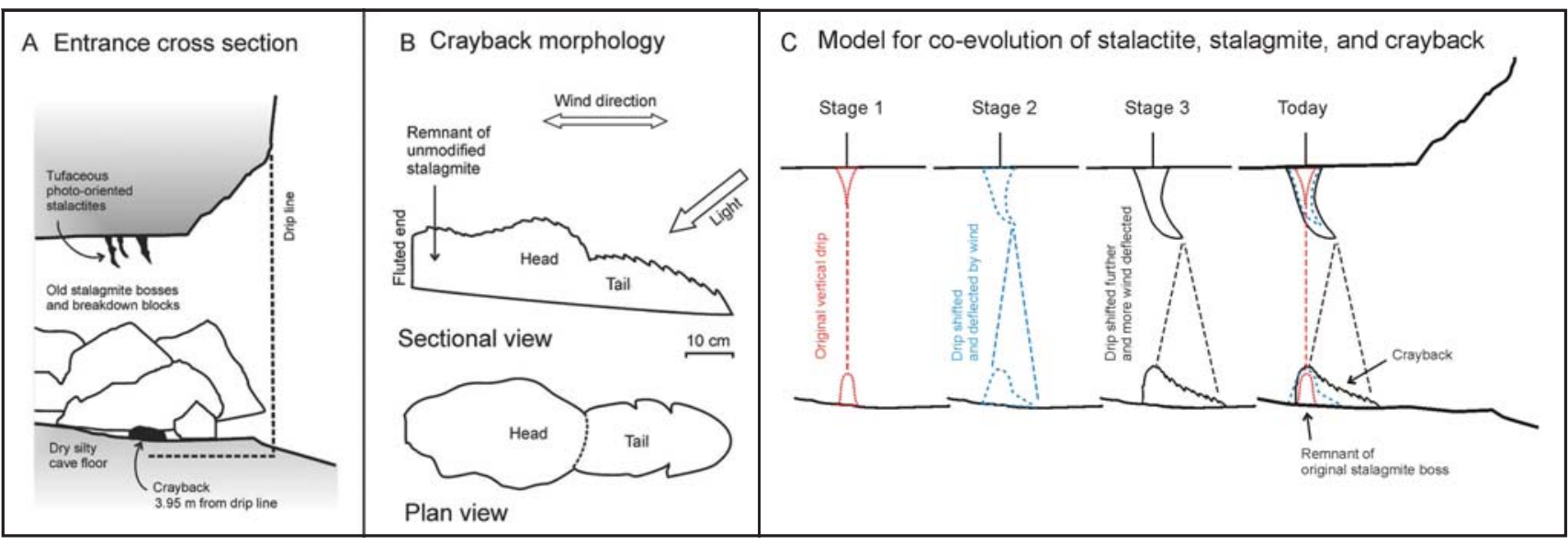

Figure 4. A. Cross section of the entrance of Painted Cave showing relationship of crayback to drip line and to the overhead tufaceous, light deflected stalactites. B. Cross section and plan view of the crayback showing the relationship of head, tail, orientation of light, and wind direction. C. Model for changing position of feed drip as overhead stalactite develops towards the light. 
craybacks than this. While the greenish colour and the presence of living cyanobacteria on the surface suggest that photosynthesis is an important activity, the fact that tails can develop on either the bright side or the shaded side suggests that the morphology is not primarily controlled by light (Cox et al., 1989a). In the Nettle Cave examples the presence of corralloid calcite mainly on the windward side and the head suggests that evaporation is important, and the predominance of silt and insect remains trapped in the cyanobacterial mucilage indicates that aeolian activity is also important (Cox et al., 1989a). The segmented macro-morphology is presumed by Cox et al. (1989a) to develop because any small irregularity casts a small shadow, the cyanobacteria do not grow so well in the shaded parts, and thus increased deposition in the bright part will create a step. Wind scatters the drips to allow simultaneous development of several steps. This explanation may work for the asymmetric crenulations, but Cox et al. (1989a, b) do not offer any model for the variation in tail behaviour. We have produced a model for development that explains the Niah crayback, which may (or may not, depending on local parameters) be applicable to other examples.

As is true for any crayback, the overall shape of the Niah crayback with the tail extending back towards the entrance is likely related to the dynamic relationship between the roof drip and stalactite, the wind, and the light. Figure $4 \mathrm{C}$ shows our proposed model of the co-evolution of cave entrance position, light and wind levels, with stalactite form, drip position, and crayback form.

We obviously cannot sample this unique example for its internal morphology, but the overall form suggests that this was originally a normal stalagmite boss (Stage 1) that has subsequently been eroded into flutes on the shaded, non-crayback side by roof drips (Figure 2). Increasing light levels resultant from external cliff retreat stimulated growth of the bluegreen mat that is presumed to be cyanobacterial. The more open site also experienced stronger air movement. This natural tunnel is situated some 15 $\mathrm{m}$ above the plain level and thus is open to wind, especially during storm events, while the cave floor provides a ready supply of dry fine-grained material for accretion on the active organic mat. The stalactite immediately above the crayback grew first vertically downwards but the tip, once in the light, began to grow preferentially towards the entrance. The locus of drip thus also moved towards the entrance and, concurrently, the organic mat shifted a little more (Stage 2). The extending tail of the crayback tracks the shifting of the locus of the drip point in association with linear deflection by wind (Stage 3 ).

This model is a special case of the general principle that we presume controls the orientation of the tail. Given adequate light (and, as discussed below, this can be very little), the tail must develop where the water falls. This is governed by the properties of the wind (strength and direction at different heights within the passage profile) and the mass and kinetic energy of the drop. Maximum deflection of the falling droplet will occur at the height of maximum air movement: this could be the floor but it could equally be the roof depending on the profile of the passage and the air flow. Ground level air movement is very often different from roof level movement in both direction and speed: the classic case is a ground-level wind of cool air in one direction simultaneous with a roof-level wind of warm air in the opposite direction (for example, Tarhule-Lips and Ford (1998) observed on Cayman Brac and Isla de Mona that in most cases hot outside air was drawn in along ceilings, cooled down inside the caves, and drained out again along the floors). If the passage cross section narrows upwards, the roof level wind can be considerably stronger than the floor level wind. Thus in different parts of the same cave the droplet may be deflected more by roof wind than by floor wind and thus the tail orientations may vary.

While it is apparent that light is an important requirement, we suggest that the control on cyanobacterial growth and detrital accretion could perhaps be explained by an alternative mechanism. The external morphology of the plates/segments in the Niah Caves example suggests an analogy to advancing dunes or perhaps krumholtz vegetation. This implies that the main growth is not so much directly on the brightest part but rather on the lee, in the region that is both less bright and less prone to dessication. The plate would thus climb up the form. Obviously this cannot be proven without a study of the internal morphology of the plates. However, many cyanobacteria do not prosper in the brightest conditions. Cox et al. (1989a) measured the light intensity at the Nettle Cave craybacks at $<10$ lux. Stal (2000) notes that photosynthesis in cyanobacteria saturates at quite low light intensities and Stolz (2000) observes that the optimum light levels for many microbial mats is as low as 0.3-3 lux. If we apply this logic to the craybacks then the best cyanobacterial growth, and thus the best conditions for photosynthetic precipitation of $\mathrm{CaCO}_{3}$ and the best conditions for trapping of detrital particles, may actually be in the shadows (at least for those examples in the brighter parts of the cave).

\section{CONCLUSIONS}

The crayback of Painted Cave, Niah National Park is valuable because of its uniqueness - it is the only one we know of in Borneo and thus deserves to be well protected - and because it is one of the very few examples outside of Australia, the classic site. Morphologically it conforms to the typical features of the Australian craybacks, although it is rather smaller. As with other craybacks, it appears to develop where light triggers colonization and subsequent photosynthetic activity. Thus light is an important requirement. However, the overall elongate form is governed largely by wind deflection of falling ceiling drips. We suggest that the simple term "crayback stalagmite" be preferred over genetic terms such as "phototropic stalagmite" because our example and 
some of those from Australia indicate that the macroform may not follow the light. We offer the suggestion that the optimum growth may not be in the brightest parts, that in some examples the crenulations may advance into the shadow rather than into the light.

\section{ACKNOWLEDGEMENTS}

Field work for this project was funded by National Science Foundation EAGER grant, \# 0952398. Thanks to Franz Kessler (and students) for survey data from Painted Cave.

\section{REFERENCES}

Barker G., Barton H., Beavitt P., Bird M., Daly P., Doherty C., Gilbertson D., Hunt C., Krigbaum J., Lewis H., Manser J., McClaren S., Paz V., Piper P., Pyatt B., Rabett R., Reynolds T., Rose J., Rushworth G. \& Stevens M., 2002 - Prehistoric foragers and farmers in South-east Asia: renewed investigations at Niah Cave, Sarawak. Proceedings of the Prehistoric Society, 68: 147-164.

Beavitt P., 1992 - Exotic animal products and Chinese trade with Borneo. Anthropozoologica, 16: 181-188.

Cox G., 1984 - Phototropic stalagmites at Jenolan Caves, $N S W$. Helictite, 22: 54-56.

Cox G., James J.M., Armstrong R.A.L. \& Leggett K.E.A., 1989a - Stromatolitic Crayfish-like stalagmites. Proceedings of the University of Bristol Spelaeological Society, 18: 339-358.

Cox G., James J.M, Legget K.E.A. \& Osborne R.A.L., 1989b - Cyanobacterially deposited speleothems: subaerial stromatolites. Geomicrobiology Journal, 7: 245-252.

Harrisson T., 1959 - New archaeological and ethnological results from Niah Caves, Sarawak. Man, 59: 53-69.

Harrisson T., 1996 - The palaeoecological context at Niah Cave, Sarawak: evidence from the primate fauna. Bulletin of the Indo-Pacific Prehistory Association, 14: 90-100.

Hunt C. \& Dykes A., 2003 - The geomorphology of the Great Cave. In: Barker G. (Ed.), The Niah Cave Project: The fourth (2003) season of fieldwork. Sarawak Museum Journal, 58 (n.s.79): 51-53.
James J.M., Jennings J.N. \& Dyson H.J., 1982 - Mineral decoration and weathering of the caves. In: Dyson H.J., Ellis R. \& James J.M. (Eds.), Wombeyan Caves. Sydney Speleological Society, Sydney: 121-136.

James J.M., Patsalides E. \& Cox G., 1994 - Amino acid composition of stromatolitic stalagmites. Geomicrobiology Journal, 12: 183-194.

Mulec J., Kosi G. \& Vrhovšek D., 2007 - Algae promote growth of stalagmites and stalactites in karst caves (Škocjanske Jame, Slovenia). Carbonates and Evaporites, 22: 6-9.

Rabett R.J., Piper P.J. \& Barker G., 2006 - Bones from 'Hell': preliminary results of new work on the Harrisson faunal assemblage from the deepest part of Niah Cave, Sarawak. In: Bacus E.A., Glover I.C. \& Pigott V.C. (Eds.), Uncovering Southeast Asia' past: selected papers from the 10th International Conference of the European association of Southeast Asian Archaeologists: 46-59.

Rowling J., 2006 - Crayback effects on stalagmites. http://www.speleonics.com.au/jills/byzone/ byzoneCray.html. Accessed 9th August 2010.

Stal L.J., 2000 - Cyanobacterial mats and stromatolites. In: Whitton B.A. \& Potts M. (Eds.), The ecology of Cyanobacteria. Kluwer Academic Publishers: 60-120.

Stolz J.F., 2000 - Structure of Microbial Mats and Biofilms. In: Riding R.E. \& Awramik S.M. (Eds.), Microbial Sediments. Springer: 1-8.

Taborŏsi D., 2006 - Biologically influenced carbonate speleothems. Geological Society of America Special Paper, 404: 307-317.

Tarhule-Lips R.F.A. \& Ford D.C., 1998 - Condensation corrosion in caves on Cayman Brac and Isla de Mona. Journal of Cave and Karst Studies, 60: 84-95. 